\title{
Assessment of laboratory waste management and laboratory staff awareness in Khartoum state
}

Hussein Abker Hussein ( $\nabla$ hussienabkar4@gmail.com )

Sudan International University

Research Article

Keywords: Waste, management, laboratory, Sudan, Khartoum

Posted Date: April 22nd, 2021

DOI: https://doi.org/10.21203/rs.3.rs-392256/v2

License: (c) (i) This work is licensed under a Creative Commons Attribution 4.0 International License. Read Full License 


\section{Assessment of laboratory waste management and laboratory staff awareness in Khartoum state}

Hussein Abker Hussein

M.SC of hematology and immunohematology Sudan international university - Khartoum- sudan

B.SC of hematology and immunohematology International university of Africa

Corresponding author :Hussein Abker Hussein :email: hussienabkar4@gmail.com

\section{Abstract \\ Background}

A good environmental health conditions is a challenge worldwide. However, Majority of Laboratory wastes extremely dangerous to the environment, animals, and human because of increasing numbers of laboratories and health facilities especially on big cities in Africa like Khartoum state Capital of Sudan.

\section{Materials and Methods}

A cross-sectional study was carried out on a group included 36 laboratories in Khartoum state from February to march 2021. Approvals have taken from each laboratory and participants voluntary informed consent and the data were collected using administered questionnaire and the data were analyzed by SPSS .

\section{Result}

Majority of the laboratories have sharp and needles waste, biological waste of human samples mainly (urine, stool, blood) and regular waste. Followed by chemical waste, culture media respectively, and radioactive waste which is the least frequent waste in Khartoum medical laboratories.

More than two thirds of laboratory personal did not get training in waste management. greater portion of laboratories have specialized company approved by authorities to collect the medical waste and treat it. similar percentage of laboratories have dustman for this job and in few laboratories the collection and treatment of the waste done by laboratory staff. 
Majority of laboratories staff are separating the medical sharps from other types of wastes in safety boxes and get rid of it by specialized company in medical waste. Few laboratories throw the safety box in landfill and reuse the safety box again and others burring or burning it.Majority of laboratory staff they don't know how to manage chemical waste.

\section{Conclusion}

Laboratories wastes are harmful to the environment, human, and animals. laboratories staff have inadequate training in waste management and disposable .there is no unique protocol for waste management and disposal followed by laboratories in Khartoum state so jeopardize laboratorian and community .

\section{Keywords}

Waste, management, laboratory, Sudan, Khartoum

\section{Introduction}

Medical laboratories are the main producer of the infectious waste, including microbiological materials, infectious sharps, and blood specimens and other types of samples. However, an improper management of the contaminated waste could leads to diseases transmission ${ }^{(1)}$. The best strategy for managing a laboratory waste aims to maximize safety and minimize environmental impact, and considers these objectives from the time of purchase ${ }^{(2)}$.however, whether the laboratories in Khartoum are following standard waste management protocol or and their staff have sufficient training in the waste management, the environmental impact of lab waste is hot question to answer in this study. The aim of this study was to assess the waste management procedures used at clinical laboratories in Khartoum, Sudan and assessment of laboratory staff training .

\section{Materials and Methods}

A cross-sectional study was carried out on group included 36 laboratories (hospital, clinic, and health center laboratories) in Khartoum state capital of Sudan from February to march 2021, laboratories from outside Khartoum state were 
excluded. Approvals have been taken from each laboratory and participants voluntary informed consent and the data were collected using administered questionnaire (provided in supplementary files) from random samples under COVID 19 regulations and the data was analyzed by SPSS version(22) and presented as frequencies.

\section{Result}

Majority of medical laboratories in Khartoum state have sharps and needles waste , biological waste of human samples mainly (urine, stool, blood) and regular waste. Followed by chemical waste, culture media respectively, and radioactive waste which is the least frequent waste which is presented in table (1). More than two thirds of laboratory staff did not get training and workshops in waste management as shown in figure (1). greater portion of laboratories have specialized company approved by authorities to collect the medical waste and treat it. similar percentage of laboratories have dustman for this job and in few laboratories the collection and treatment of the waste done by laboratory staff which is illustrated in figure(2) .

Majority of laboratories staff are separating the medical sharps from other types of wastes in safety boxes and get rid of it by specialized company in medical waste. Few laboratories throw the safety box in landfill and reuse the safety box again and others burring or burning it as shown in figure $(3,4)$. Majority of laboratory staff they don't know how to manage chemical waste as presented in table(2). Regarding chemical and biological waste there is variation in disposal methods as shown in table $(3,4)$. 
Table(1): Frequencies of laboratory waste in medical laboratories in Khartoum state

\begin{tabular}{|l|l|l|}
\hline Waste types & Number & Frequency \\
\hline Needles and sharps & 33 & $91.7 \%$ \\
\hline Biological(patients samples) & 34 & $94.4 \%$ \\
\hline Bacteria culture media & 8 & $22.2 \%$ \\
\hline Chemicals & 12 & $33.3 \%$ \\
\hline Radioactive & 3 & $8.3 \%$ \\
\hline house & 33 & $91.7 \%$ \\
\hline
\end{tabular}

Table(2): laboratory waste Disposal protocols awareness among laboratory staff

\begin{tabular}{|l|l|}
\hline waste & $\begin{array}{l}\text { Frequency of staff don't know } \\
\text { laboratory waste Disposal protocols }\end{array}$ \\
\hline chemicals & $55.6 \%$ \\
\hline biological & $19.4 \%$ \\
\hline Culture media & $8.3 \%$ \\
\hline radioactive & $11.1 \%$ \\
\hline
\end{tabular}

Table (3): Disposal of chemical waste protocols followed by laboratory staff

\begin{tabular}{|l|l|}
\hline protocol & Frequency \\
\hline sewage & $27.8 \%$ \\
\hline Pour it in street & $2.8 \%$ \\
\hline Pour it far away from buildings & $5.6 \%$ \\
\hline Pour it in a well & $8.3 \%$ \\
\hline
\end{tabular}

Table(4): Disposal of biological waste protocols followed by laboratory staff

\begin{tabular}{|l|l|}
\hline protocol & Frequency \\
\hline Medical waste company protocol & $8.4 \%$ \\
\hline Ordinary waste company & $55.6 \%$ \\
\hline Landfill & 2.8 \\
\hline burn & 13.9 \\
\hline
\end{tabular}




\section{training and workshops}

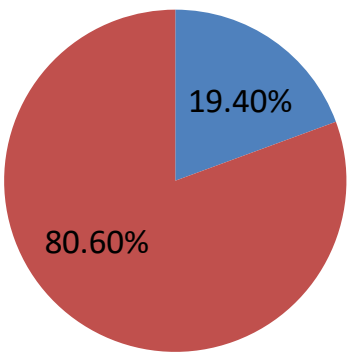

- Trained

not trained

Figure(1): frequency of laboratory staff training in waste management

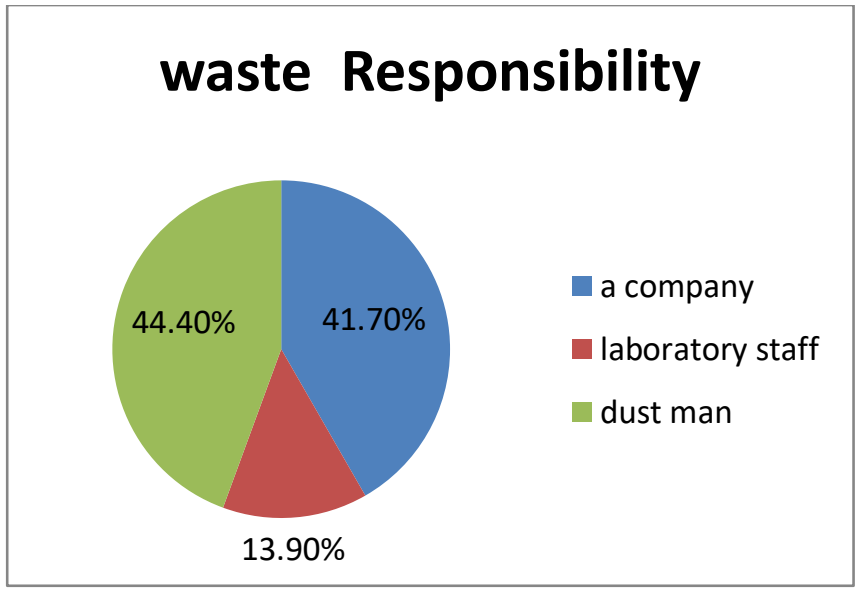

Figure (2): waste management responsibility

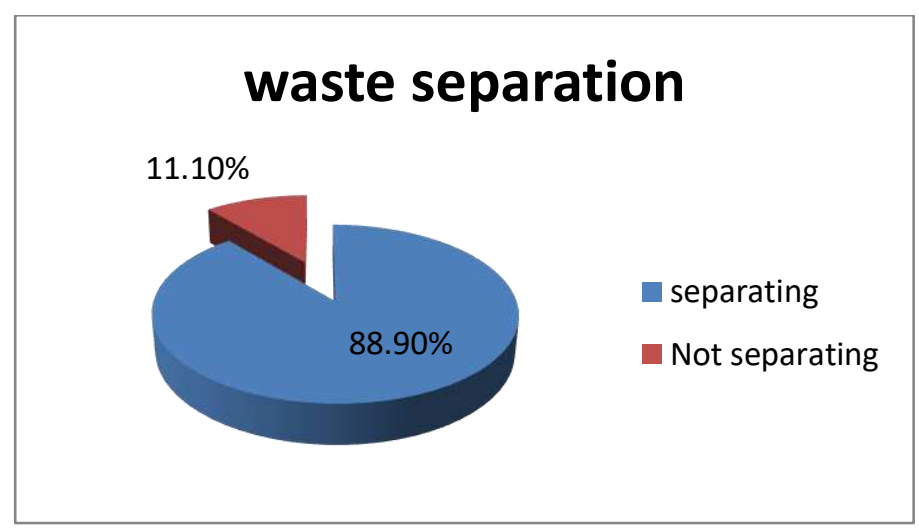

Figure(3 ) laboratory waste separation in medical laboratories 


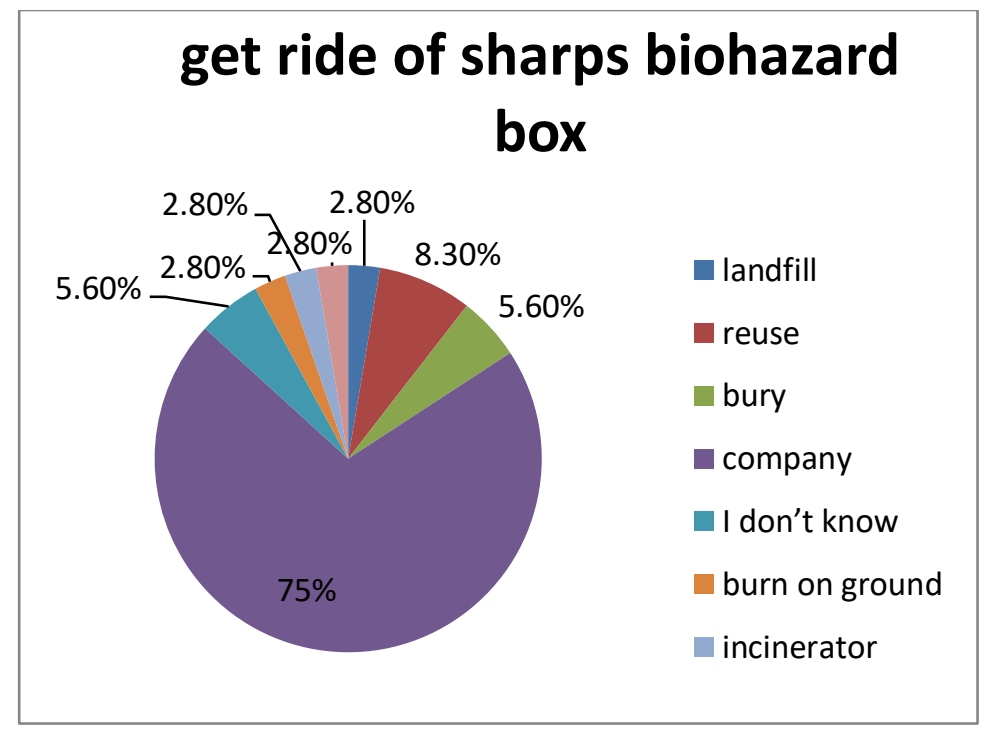

Figure (4): different protocols of biohazards box disposal

\section{Discussion}

The results showed there is no unique protocol followed in Khartoum state clinical labs for laboratory waste management specially infectious waste as well as inadequate training for laboratories staff. Neglecting guideline of lab waste management and disposal jeopardize lab staff, dustman, and others life with infectious diseases. These results were supported by many published studies.

Saad SA found in his study that most of waste, office, general, food, construction debris, and hazardous chemical materials were all mixed together as they are produced in hospitals, collected, and finally disposed of. a small part of infectious, and sharps waste in some health facilities are gathered separately and handled in a central incinerator. In Khartoum state no guideline for hospital waste, or even hazardous waste only some general environmental guideline. At the hospital level, no policies or rules were existed, except in the radiotherapy center, where they treat radioactive wastes by the laws of the Sudanese Atomic Agency. Urgent 
actions are required for the treatment and prevention of hazards related with this type of waste ${ }^{(3)}$.

Hassan AA et al. found that Sharps management is inefficient in Khartoum hospitals. as all wastes are gathered without separation and disposed improperly, especially needles ${ }^{(4)}$.

Mukhtar CM found that waste management guidelines, waste collection program, radioactive waste container and hazards chemical waste management are not available in National Public Health Laboratory ${ }^{(5)}$.

Elnour AM et al reported that The nursing and sanitation staff at the main hospitals of the White Nile State in Sudan recorded significant improvement in their knowledge and practice with regard to hospital waste management immediately after the educational intervention program and three months later ${ }^{(6) .}$

\section{Conclusion}

Laboratories wastes are harmful to the environment, human, and animals because it contain infectious material, sharp materials, chemical reagents, and radioactive reagents. laboratories staff have inadequate training in waste management and disposable .there is no unique protocol for waste management and disposal followed by laboratories in Khartoum state so jeopardize laboratorian and community . thus laboratories should give their staff training in waste management and disposable and get rid of their waste only through specialized medical waste company. Government should develop our national waste management and disposable guideline based on the international guideline and implement it with follow up in order to have clean environment from laboratories waste in Sudan. 


\section{Declarations}

Ethical approval

Collection of Data were approved by of Khartoum State Ministry of Health

Research Department ethical committee.

Informed consent

Informed consent was obtained from all individual participants included in the study.

\section{Ethical guidelines}

All procedures performed in studies involving human participants were in accordance with the ethical standards of Khartoum State Ministry of Health Research Department ethical committee and with the 1964 Helsinki declaration and its later amendments or comparable ethical standards.

\section{Consent for publication}

Not applicable availability of Data and Materials

All data generated or analyzed during this study are available from the corresponding author on reasonable request.

Competing interests

I declare that I have no competing of interests

Funding

no funding was received

Author's contributions

Not applicable

\section{Acknowledgment}

I Acknowledge all laboratories that participate in this study 


\section{References}

1- Askarian M, Motazedian N, Palenik CJ. Clinical laboratory waste management in Shiraz, Iran. Waste management \& research. 2012 Jun;30(6):631-4.

2- National Research Council. Prudent practices in the laboratory: handling and management of chemical hazards, updated version.

3- Saad SA. Management of hospitals solid waste in Khartoum State. Environmental monitoring and assessment. 2013 Oct;185(10):8567-82.

4- Hassan AA, Tudor T, Vaccari M. Healthcare waste management: A case study from Sudan. Environments. 2018 Aug;5(8):89.

5- Mukhtar CM. Assessment of Facilities and Safety in National Public Health Laboratory-Sudan-2015 (Doctoral dissertation, Sudan University of Science and Technology).

6- Elnour AM, Moussa MM, El-Borgy MD, Fadelella NE, Mahmoud AH. Impacts of health education on knowledge and practice of hospital staff with regard to Healthcare waste management at White Nile State main hospitals, Sudan. International journal of health sciences. 2015 Jul;9(3):315. 
Figures

\section{training and workshops}

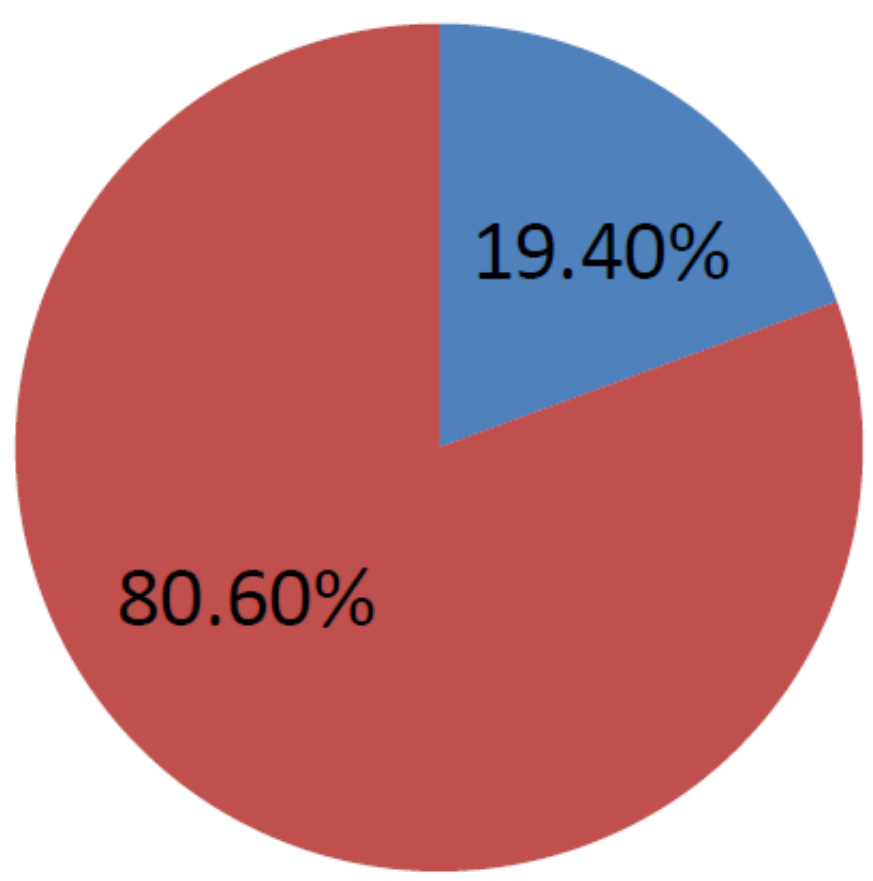

- Trained

Not trained

\section{Figure 1}

frequency of laboratory staff training in waste management 


\section{waste Responsibility}

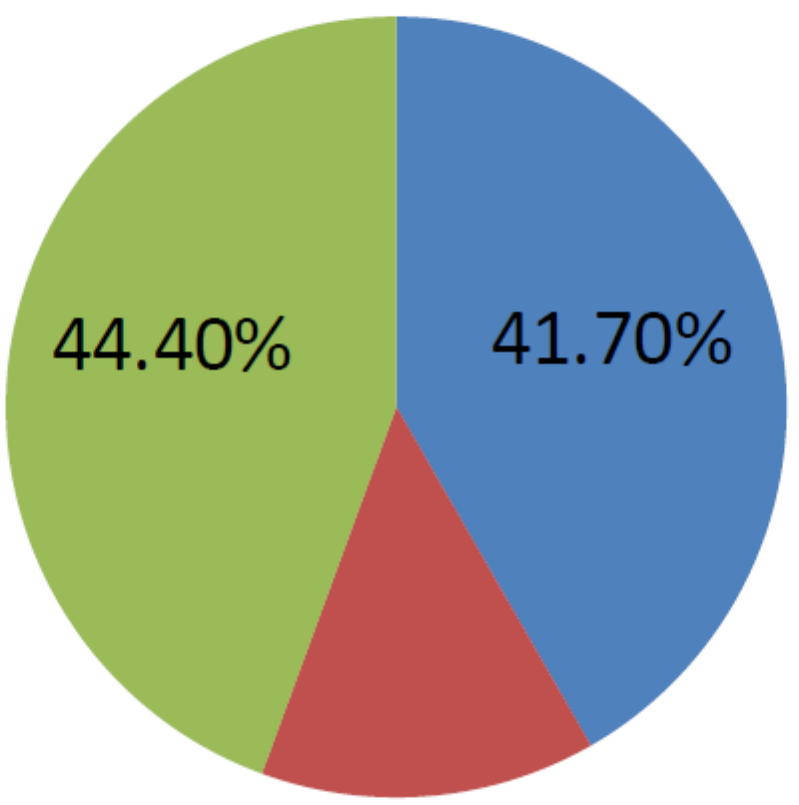

a company

$13.90 \%$

- laboratory staff

dust man

Figure 2

waste management responsibility 


\section{waste separation}

\section{$11.10 \%$}

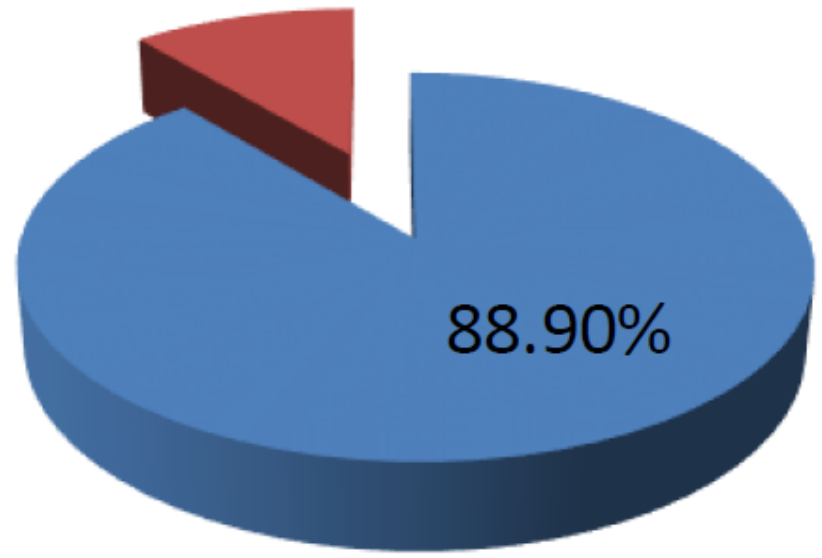

separating

Not separating

\section{Figure 3}

laboratory waste separation in medical laboratories 


\section{get ride of sharps biohazard box}

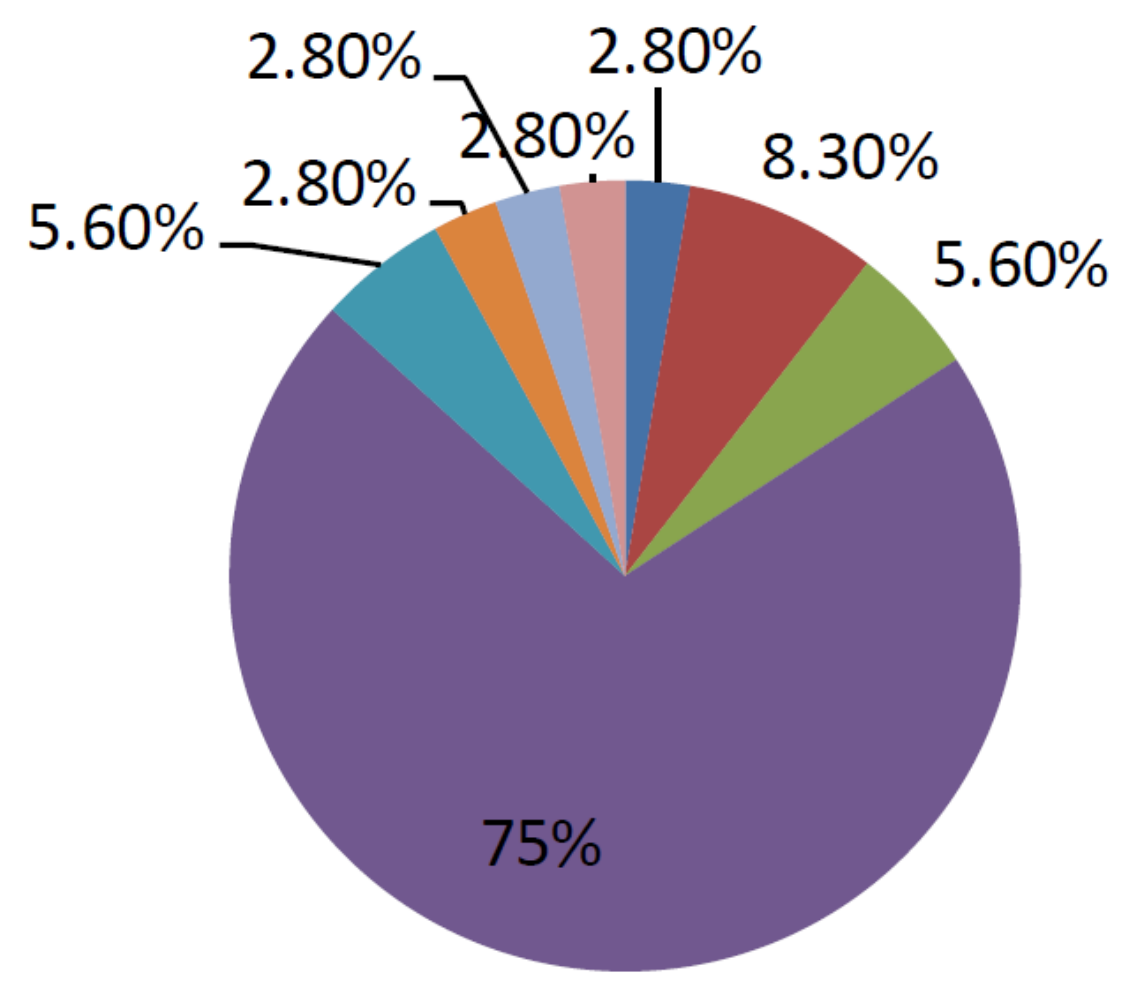

- landfill

reuse

bury

company

- I don't know

burn on ground

incinerator

Figure 4

different protocols of biohazards box disposal

\section{Supplementary Files}

This is a list of supplementary files associated with this preprint. Click to download.

- questionareconverted.pdf 